\title{
ISM 2.45 GHz MİKROŞERİT İMPLANT ANTEN TASARIMI VE DOKU İÇİ ÖLÇÜMLERİ
}

\author{
Fatih ALPER*, Özlem COŞKUN
}

Süleyman Demirel Üniversitesi, Mühendislik Fakültesi, Elektrik ve Elektronik Mühendisliği Bölümü, Isparta, Türkiye

\begin{tabular}{|c|c|}
\hline Anahtar Kelimeler & Öz \\
\hline $\begin{array}{l}\text { Implant Anten, } \\
\text { Doku İçi Uygulamalar, } \\
\text { Biyotelemetri, } \\
\text { Mikroşerit Anten. }\end{array}$ & 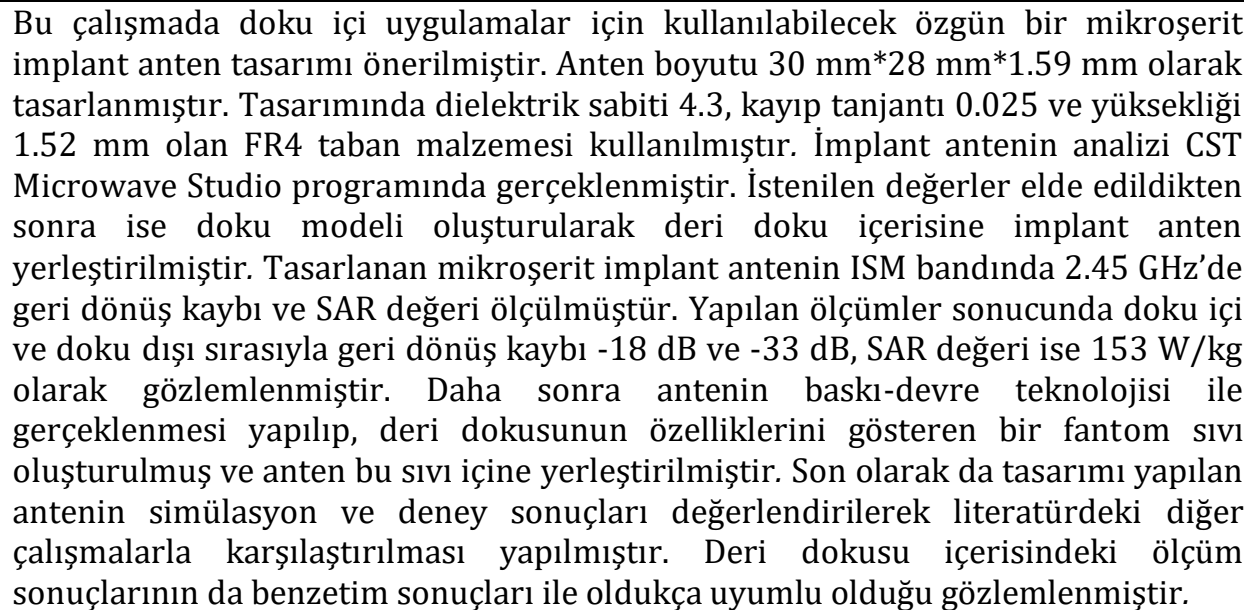 \\
\hline
\end{tabular}

\section{ISM 2.45 GHZ MICROSTRIP IMPLANT ANTENNA DESIGN AND IN-TISSUE MEASUREMENTS}

\section{Keywords Implant Antenna, In-Tissue Application, Biotelemetry, Microstrip Antennas.}

\begin{abstract}
In this study, a micro-strip implant antenna that can be used in-tissue applications was proposed. Antenna size was designed as $30 \mathrm{~mm} * 28 \mathrm{~mm} * 1.59 \mathrm{~mm}$. In the design, a FR4 substrate material was used whose permittivity is 4.3 , loss tangent is 0.025 and height is $1.52 \mathrm{~mm}$. The analysis of the implant antenna was simulated in the CST Microwave Studio program. After obtaining the desired performance, a tissue model was created and an implant antenna was placed in the skin tissue. Return loss and SAR value of the designed antenna were measured in the $2.45 \mathrm{GHz}$ ISM band. As a result, return losses were observed as $-18 \mathrm{~dB}$ and $-33 \mathrm{~dB}$ and SAR was $153 \mathrm{~W} / \mathrm{kg}$ inside and outside the tissue respectively. Then, the antenna was manufactured with PCB and a phantom liquid was created that provides the electromagnetic properties of the skin tissue and the antenna was placed in this liquid. Finally, the simulation and experiment results of the designed antenna were evaluated and compared with literature studies. It has been observed that the measurement results in the skin tissue are well aligned with the simulation results.
\end{abstract}

\section{Alıntı / Cite}

Alper, F., Coșkun, Ö., (2020). ISM 2.45 GHz Mikroșerit İmplant Anten Tasarımı ve Doku İçi Ölçümleri, Mühendislik Bilimleri ve Tasarım Dergisi, 8(2), 541-551.

\begin{tabular}{l|l|l}
\hline Yazar Kimliği / Author ID (ORCID Number) & \multicolumn{3}{|l}{ Makale Süreci / Article Process } \\
\hline F. Alper, 0000-0003-3195-9727 & Başvuru Tarihi / Submission Date & 12.02 .2020 \\
Ö. Coşkun, 0000-0001-8800-4433 & Revizyon Tarihi / Revision Date & 16.03 .2020 \\
& Kabul Tarihi / Accepted Date & 04.04 .2020 \\
& Yayım Tarihi / Published Date & 25.06 .2020 \\
\hline
\end{tabular}

\footnotetext{
* İlgili yazar / Corresponding outhor: fatihalper64@gmail.com,+90-545-684-0323
} 


\section{Giriş (Introduction)}

Telemetri bir sistemin uzaktan ulaşılamayan bir bölgesini kontrol edilmesi ve izlenmesidir. İnsanlar ve hayvanlar için kullanılan telemetriye ise biyotelemetri adı verilmektedir. Biyotelemetri sistemlerinin temelleri, Amerikan Ulusal Havacılık ve Uzay Dairesi NASA tarafından 1958 yılında ortaya çıkarılmıștır. Uzaya gönderilen astronotların fizyolojik parametrelerinin, yeryüzünde bulunan sağlık çalışanlarına iletilmesi için yapılan araştırmalar biyotelemetri sistemlerinin ana gövdesini oluşturmuştur (Singh, 2005). Aynı yll içerisinde Ake Senning'in ilk kez bir kalp pilini insan vücudu içerisine yerleștirmesi de implant edilebilir biyomedikal cihazların sivil amaçlı kullanımı olarak günlük yaşantımızda yer almıştır (Hall ve Hao, 2012).

Biyotelemetri sistemlerinin ana görevi ise, insan vücudundaki hayati parametrelerin uzaktan takibini yapmak ve doktorlara hastalıkların teşhis ve tedavisinde yardımcı olmaktır. Günümüz biyotelemetri uygulamalarında EKG, EMG, EEG, kan basıncı, kan akışı ve vücut sıcaklı̆̆ı gibi birçok değerin uzaktan ölçülmesi mümkündür. Uygulama alanlarındaki bu çeşitlik biyotelemetri sistemlerinde kullanılacak olan biyomedikal cihazların farklılaşmasını sağlamakta ve cihazların tasarımlarını gün geçtikçe değiștirmektedir. Özellikle hastalıkların önceden teşhisinin oldukça önem kazandığı son yıllarda biyotelemetri uygulamalarının gereksinimlerini karşılayacak yenilikçi elemanların (anten, mikroişlemci/ mikrodenetleyici, sensör gibi) geliştirilmesine/ üretilmesine ihtiyaç duyulmaktadır. Bu sistemlerin önemli bileşenlerinden biri olan anten elemanı, verilerin iletilmesini sağlarken, sistemin küçültülmesinde de oldukça kritik bir rol oynamaktadır. Bu bağlamda biyo-uyumlu ve uygulama gereksinimlerini karşılayacak minyatür yapılı anten tasarımlarının geliştirilmesi tıbbi sistemin bașarımı açısından üstesinden gelinmesi gereken önemli bir parametredir (Topsakal, 2009, Armağan ve Kahriman, 2016).

Tıbbi uygulamalarda kullanılan anten tasarımları genel olarak, yutulabilir, giyilebilir ve implant antenler olmak üzere üç grupta incelenmiştir. Yutulabilir antenler, vücut içindeki değişkenlik gösteren bazı parametrelerin (örneğin; ISI) aktarılmasında ve kolon kanserinin teşhisinde kullanılmaktadır (Yang vd., 2008). Giyilebilir antenler ise vücut yüzeyine yerleștirilerek kalp ritmi, kandaki oksijen miktarı ve kandaki şeker seviyesi gibi değerlerin ölçümünde kullanılabilmektedirler (Lee, 2015). İmplant antenler ise vücut içerisinde belirli bir konuma sabit olarak yerleştirilerek mikrodalga görüntüleme, kalp ritim bozuklukları, kanser teşhis ve tedavisinde kullanılmaktadır (Sondas vd., 2014).

\section{Kaynak Araștırması (Literature Survey)}

Gözel vd. (2019), vücuda yerleştirilen biyomedikal antenler üzerine çalışılmıştır. Bir anten tasarımı yapılarak, bu anten simüle edilmiştir. Çalışmada kullanılmak üzere rezonans frekansı $868 \mathrm{MHz}$ UHF bandında, H şeklinde bir mikroşerit anten tasarımı yapılmıştır. Tasarlanan antende alt yapı malzeme olarak FR4 kullanılmıştır. Simülasyon için oluşturulan doku üç farklı katmandan oluşmaktadır. Bu katmanlar kas, yağ ve deriden meydana gelmektedir. Anten bu doku örneğinde deri ile yağ katmanı sınırındadır. Simülasyon sonucuna göre SAR değeri CST simülasyon programında 396,8 W/kg olarak hesaplaşmıştır. Çalışmada diğer çalışmalarla karşılaştırma yapılarak ortalama bir değer bulunduğu görülmüştür. Ayrıca doku içinde tasarlanan antenlerin çalışma frekansının ayarlanabilm esi, antenin doku içindeki yerine, dokunun iletkenlik ve dielektriği gibi birçok parametre bağlı olduğu gözlemlenmiştir.

Yeap vd. (2019), implant edilebilir çift bant çalışan bir anten üzerine çalışma yapmıştır. Tasarlanan antenin rezonans frekansları $402 \mathrm{MHz}$ ve $2.45 \mathrm{GHz}$ dir. Antende malzeme olarak R03210 kullanılmıştır. Doku içi uygulamalarda kullanılan antenlerin boyutları oldukça küçük tasarlanmıştır. Bu çalışmada kullanılan antenin boyutları $22 \mathrm{~mm} * 16 \mathrm{~mm} * 1.27 \mathrm{~mm}$ 'dir. Yapılan simülasyon sonuçlarına göre SAR değeri $402 \mathrm{MHz}$ ve $2.45 \mathrm{GHz}$ frekanslarında sırası ile 0.352 ve $0.054 \mathrm{uW} / \mathrm{kg}$ olarak hesaplanmıştır. Bu değerler IEEE C95.1-1999 tarafından belirlenen sınırların altında olduğu görülmüştür. Daha sonra anten ilk önce insan derisine koyularak, ardından parçalanmış domuz etine koyularak ölçümler yapılmıştır. Ölçümler sonucu antenin iyi radyasyon özelliklerine sahip olduğu ve SAR değerinin düşük olmasıyla kullanılabilir bir anten olduğu gözlemlenmiştir.

Kumar ve Raj (2017), bu çalışmada biyomedikal uygulamalar için yeni bir implant anten tasarımı yapılmıştır. Böyle bir çalıșma ile kablosuz olarak insan vücudundaki bazı olayları incelemek hedeflenmiștir. Tasarlanan anten dielektrik malzemesi teflon olan bir yama antendir. Boyutları 16 mm* 16 mm* 1 mm'dir. Önerilen antenin frekansı 2.4-2.48 GHz olarak tasarlanmıştır. İnsan dokusunu tek katmanlı olarak düşünülmüștür. Simülasyon olarak kas dokusunun özellikleri kullanılmıștır. Simülasyonlar CST üzerinden yapılmıştır. Daha sonra dokunun fantom modeli oluşturularak ölçümler gerçeklenmiştir. Yapılan ölçümler sonucunda antenin geri dönüş kaybı $-37 \mathrm{~dB}$ olarak gözlemlenmiştir. ISM bandında tasarlanan bu antenin boyutunun küçük olması ve yapılan ölçümler sonucunda bu tür uygulamalar için kullanılması uygun olduğu gözlemlenmiştir. 
Yamaç, (2015), biyomedikal telemetri için implant edilebilen mikroşerit anten tasarımı sunmuştur. Tanıtılan anten 402-405 MHz MICS bandını ve 2.45 GHz ISM bandını kapsamaktadır. Anten implant edilebilir olması için antenin küçük boyutlarda olması gerekmektedir. Tanıtılan antenin boyutları $10.5 \mathrm{~mm} * 11.5 \mathrm{~mm} * 1.27 \mathrm{~mm}$ 'dir. Anten Rogers 3010 taban malzemesi ile tasarlanmıștır. İmplant antenin analizi CST Microwave Studio programı kullanılarak yapılmıştır. Ayrıca tek katmanlı deri dokusu fantom modeli oluşturularak da ölçümler yapılmıştır. Bu çalışmada ek olarak esnekliği göstermek adına üç farklı boyutta anten tasarımı da sunulmuştur. Yapılan ölçümler sonucunda MICS bandında \%42,1 ve ISM bandında \%5,8 bant genişliği sunmaktadır. Anten kazançları sırasıyla 39 dB ve 22.9 dB'dir. SAR değeri olarak da sırasıyla $369 \mathrm{~W} / \mathrm{kg}$ ve $396.4 \mathrm{~W} / \mathrm{kg}$ 'dır. Bu ölçümler ışığında sonuçların diğer çalışmalara göre tatmin edici olduğu gözlemlenmiştir.

See vd. (2015), 434 MHz'de nöro motor protez için iki implant anten sunulmuştur. Bu anten dipol bir implant antendir. Antenin simülasyonunda üç boyutlu olan deri, yağ ve kas dokudan oluşan doku modeli kullanılmıştır. Anten kalınlığı $0.8 \mathrm{~mm}$ olup dokudan $20 \mathrm{~mm}$ uzağa konumlandırılmıştır. Tasarımı sunulan antenin simülasyonları HyperLynx 3D electromagnetic software programı kullanılmıștır. Antenin yönlülüğü $3.8 \mathrm{~dB}$ ve bant genişliği \%4,6 olarak gözlemlenmiştir. Yapılan ölçümlerde $8 \mathrm{~cm}$ de $-14 \mathrm{~dB}$ kayıp olduğu gözlemlenmiştir. İleriki çalışmalar için bant genişliği artırılarak daha iyi sinyal aktarımı önerilmiştir.

Huang ve Kishk (2011), insan vücuduna yerleştirilen kalp pili için bir implant anten tasarımı yapılmıştır. Bu anten MICS bandında $403 \mathrm{MHz}$ de çalışmaktadır. Anten, spiral şeklinde tasarlanmış mikroşerit bir antendir. Taban malzemesi olarak Rogers kullanılmıştır. Doku olarak kas dokuya yerleştirilmiştir. Ölçümler ilk olarak HFSS simülasyon programında gerçekleşmiş daha sonra kas dokusunun fantom eşdeğer sıvisı oluşturularak ölçümler tamamlanmıştır. Ölçüm sonuçlarına göre antenin doku içindeki $\mathrm{S}_{11}$ 'i $403 \mathrm{MHz}$ merkez frekansında $-18 \mathrm{~dB}$ iken anten boşluktayken $\mathrm{S}_{11}$ 'i $489 \mathrm{MHz}$ merkez frekansında -3 dB olmaktadır. Ölçülen SAR değeri ise 2.749 W/kg olarak gözlemlenmiştir. Yapılan gözlemler sonucu simülasyon ile ölçümlerin birbirine yakın olduğu görülmüştür.

Kiourti ve Nikita (2012), bu çalışmada implant antenlerin dokudaki tasarım ve elektromanyetik etkileri incelenmiștir. Bunun için dört farklı frekansta (402 MHz, $433 \mathrm{MHz}, 868 \mathrm{MHz}, 915 \mathrm{MHz}$ ) PIFA anten tasarımları yapılmıştır. Bu çalışmada anten kafadaki deri doku özelliklerine göre ölçümler yapılmıştır. Ölçümler deri dokusunun eşdeğer fantom modeli oluşturularak yapılmıştır. Ölçümler sonucunda $402 \mathrm{MHz}, 433 \mathrm{MHz}, 868 \mathrm{MHz}$, $915 \mathrm{MHz}$ frekanslarında sırası ile SAR değeri $1 \mathrm{~g}$ dokuda $324.74 \mathrm{~W} / \mathrm{kg}, 309.74 \mathrm{~W} / \mathrm{kg}, 296.94 \mathrm{~W} / \mathrm{kg}, 294.86 \mathrm{~W} / \mathrm{kg}$ olarak ölçülmüştür. Antenlerin kazançları sırası ile 36.9 dB, 35.99 dB, 35.14 dB, 32.94 dB olarak gözlemlenmiştir.

Duan vd. (2012), diferansiyel olarak beslenen dual band bir implant anten tasarımı sunmuştur. Bu besleme şekli olarak literatürdeki ilk implant anten tasarımıdır. Bu anten 433.9 MHz ve 542.4 MHz olmak üzere iki rezonans frekansta çalışmaktadır. Anten üç katmanlı doku modelinin her katmanına koyularak ölçüm yapılmıştır. Yapılan çalışma ilk önce HFSS programında simüle edilmiş, daha sonra fantom sıvıda ölçüm yapılmıştır. Yapılan ölçümler sonucunda antenin tek katmanlı doku ile çok katmanlı doku arasında çok bir fark olmadı̆̆ı gözlemlenmiştir. Ayrıca değişik dokularda yapılan ölçümlerden yola çıkarak, deri ve kas dokuda yapılan ölçümler birbirine yakın yă̆ dokuda ise biraz düşüktür. Bunun nedeni yağ dokunun iletkenlik ve geçirgenliğinin yüksek, dielektriğinin ise düşük olmasından kaynaklanmaktadır. Yapılan ölçümlerde SAR değeri $10 \mathrm{~g}$ dokuda $423 \mathrm{MHz}$ ve $532 \mathrm{MHz}$ de sırası ile y-z düzleminde $0.930 \mathrm{~mW} / \mathrm{kg}$ ve $0.936 \mathrm{~mW} / \mathrm{kg}$, x-z düzleminde $0.895 \mathrm{~mW} / \mathrm{kg}$ ve $0.933 \mathrm{~mW} / \mathrm{kg}$ olarak gözlemlenmiștir.

\section{Materyal ve Yöntem (Material and Method)}

\section{1. İmplant Antenin Tasarımı ve Gerçeklenmesi (Design and Verification of Implant Antenna)}

İmplant anten tasarımında ilk olarak bilgisayar ortamında CST simülasyon programında doku modeli oluşturularak simülasyon yapılmıştır. İkinci olarak da dokuların eşdeğer sıvısı oluşturularak ölçümler gerçeklenmiştir. Bunun amacı direk insan vücudunda ölçüm yapılamayacak olmasıdır. Literatürde fantom model kullanarak ölçüm yapan birçok çalışma vardır (Merli vd., 2011; Polat, 2011; Kumar ve Raj, 2017). Aynı zamanda bu ölçümler hayvanlar üzerinde de yapılabilmektedir (Merli vd., 2011; Yeap vd., 2019).

İmplant anten tasarımında dikkat edilmesi gereken en önemli parametrelerden bir tanesi antenin doku içi uygulamalarında uygulanacağı için küçük boyutlarda gerçeklenmesi gerekmektedir. Küçük boyutlarda tasarlanan antenin istenilen frekansta ve istenilen $\mathrm{S}_{11}$ performansını elde etmek oldukça güçtür. Bu gerekçeler göz önünde bulundurulduğunda $30 \mathrm{~mm}$ * $28 \mathrm{~mm}$ büyüklüğe sahip anten tasarımı gerçekleștirilmiştir. Dielektrik malzemesi FR4 olan yama anten tasarımı kullanılmıştır. Bu çalışma 2.45 GHz ISM bandında yapılmaktadır. 
Küçük boyuttaki bir antenin rezonans frekansını ayarlamak oldukça zordur. Merkez frekansını ayarlamak için birçok yöntem kullanılabilir. Bu tasarımda Şekil 1'de gösterildiği gibi antenin ön yüzüne besleme hattının başlangıcının sağ ve sol tarafına toprak ile bağlantılı iletken koyularak merkez frekansı ayarı yapılmıştır.

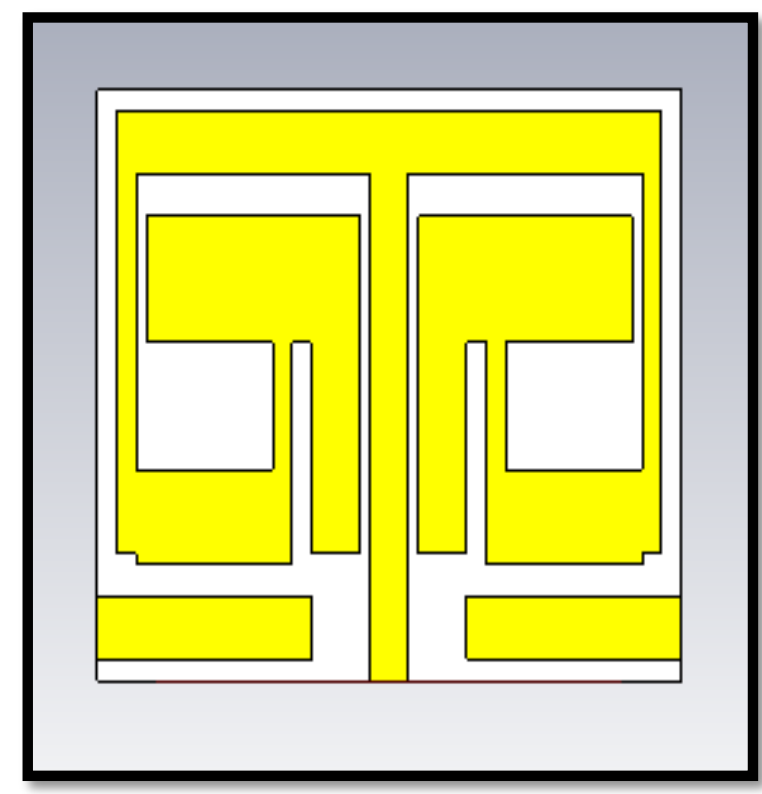

Şekil 1. Mikroșerit antenin simülasyon görüntüsü (Simulation view of microstrip antenna)

Tasarımı yapılan mikroșerit antenin ölçü parametreleri Şekil 2'de gösterilmiştir.

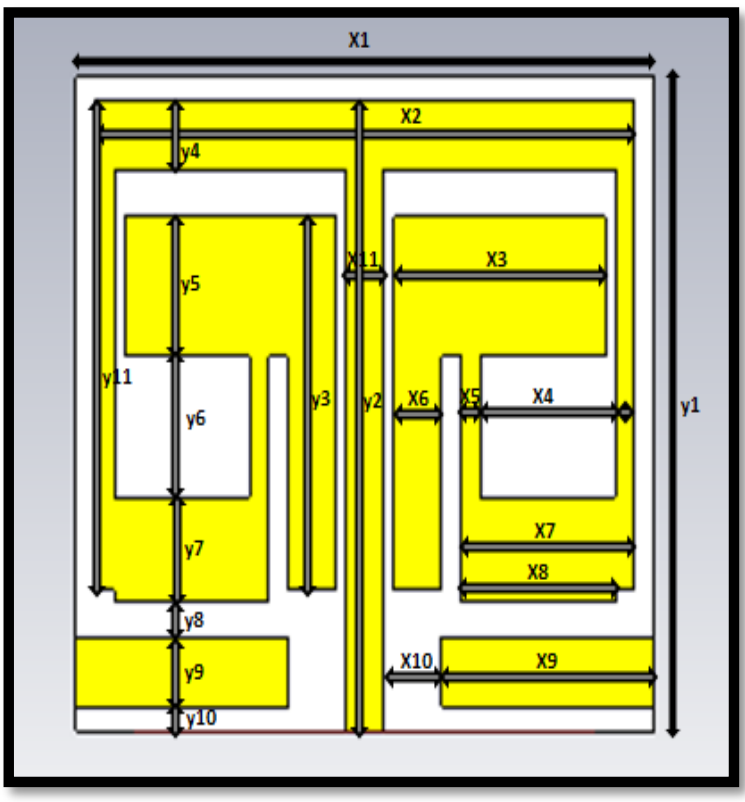

Şekil 2. Mikroşerit antenin uzunluk parametreleri (Lenght parameters of microstrip antenna)

Așağıdaki Tablo 1'de antenin uzunluk parametreleri verilmiștir. Yama antenin simülasyonunda dielektrik malzemenin kalınlığı $1.52 \mathrm{~mm}$ ve iletkenin kalınlığı ise 0.035 mm olarak alınmıştır.

Tablo 1. Tasarlanan mikroșerit antenin uzunluk parametreleri (Lenght parameters of designed microstrip antenna)

\begin{tabular}{|c|c|c|c|c|c|c|c|c|c|c|c|}
\hline Uzunluk Parametreleri & $\mathbf{X 1}$ & $\mathbf{X 2}$ & $\mathbf{X 3}$ & $\mathbf{X} 4$ & $\mathbf{X 5}$ & $\mathbf{X 6}$ & $\mathbf{X 7}$ & $\mathbf{X 8}$ & $\mathbf{X 9}$ & $\mathbf{X 1 0}$ & $\mathbf{X 1 1}$ \\
\hline Uzunluk Değerleri (mm) & 30 & 28 & 11 & 7 & 1 & 2.5 & 9 & 8 & 11 & 2.5 & 2 \\
\hline Uzunluk Parametreleri & Y1 & Y2 & Y3 & Y4 & Y5 & Y6 & Y7 & Y8 & Y9 & Y10 & Y11 \\
\hline Uzunluk Değerleri (mm) & 28 & 27 & 16 & 3 & 6 & 6 & 4.5 & 1.5 & 3 & 1 & 21 \\
\hline
\end{tabular}


Mikroşerit antenin simülasyonu yapıldıktan sonra antenin baskı-devre teknolojisi ile gerçeklenmesi yapılıştır. Gerçeklenmesi yapılan mikroşerit antenin görüntüsü Şekil 3'de verilmiştir.

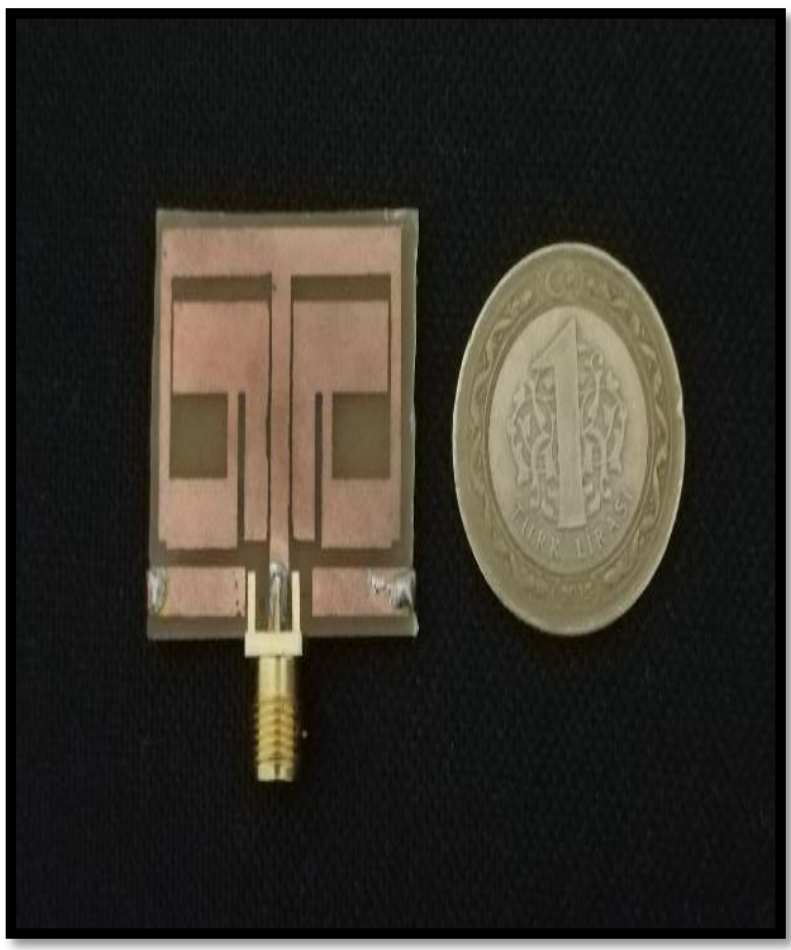

Şekil 3. Tasarımı yapılan antenin gerçeklenmiş görüntüsü (Verification view of designed antenna)

\subsection{Doku Modelinin Oluşturulması (Composing of Tissue Model)}

Bu çalışmada üç katmanlı doku modeli kullanılmıştır. Önceki bölümde bahsedildiği gibi ölçümlerin yapılmasında direkt olarak insan vücudu kullanılması mümkün olmadığı için, simülasyon aşamasında en yakın sonuçları elde edebilmek amacıyla bu şekilde tasarım yapılmıştır. Geçmiş yıllarda yapılan çalışmalar değerlendirildiğinde çalıșmaların büyük çoğunluğunda üç katmanlı tasarımın yapıldığı gözlemlenmiștir (Kim ve Rahmat-Samii, 2004; Karaçolak vd., 2008; Almari vd., 2013; Doddipalli vd., 2017; Gözel vd., 2019). Bu tasarım CST Microwave Studio programı kullanarak tasarlanmış ve ölçümler yapılmıştır.

Üç boyutlu doku modeli Şekil 4'de gösterilmiştir. Tasarımı yapılan implant anten deri dokunun içine yerleștirilmiștir.

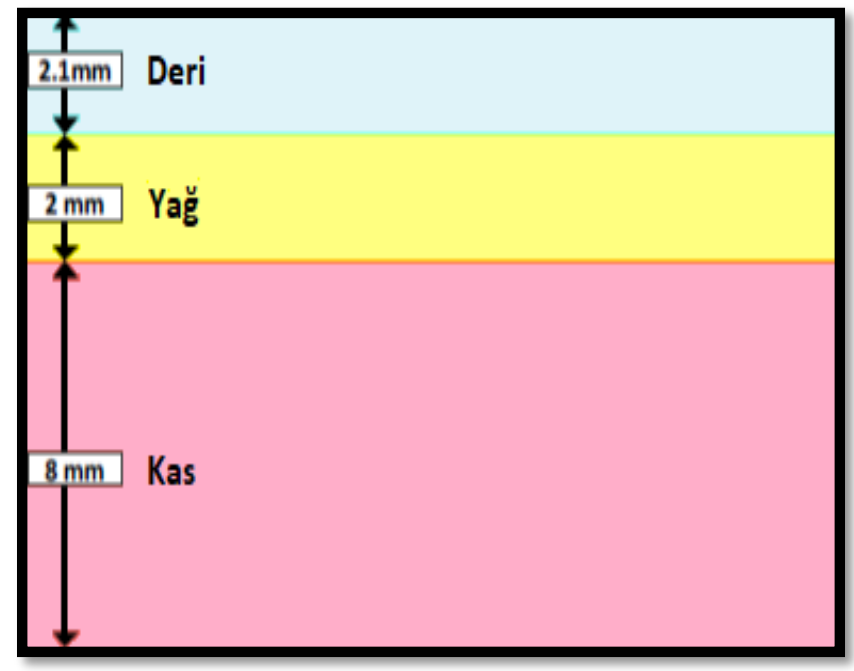

Şekil 4. Üç katmanlı doku modeli (Three layered tissue model) 


\subsection{Doku Fantom Sıvısının Oluşturulması (Composing of Tissue Phantom Liquid)}

Bu çalışmada $2.45 \mathrm{GHz}$ ISM bandına göre fantom sıvı oluşturulmuştur. Kullanılan malzemeler ve oranları aşağıdaki Tablo 2'de belirtilmiştir.

Tablo 2. Deri dokunun MICS ve ISM bandında Fantom İçeriği (Phantom content in MICS and ISM band of skin tissue)

\begin{tabular}{|c|c|c|}
\hline KULLANILAN MALZEMELER & $\begin{array}{c}\text { MICS BANDI } \\
(402-405 \mathrm{MHz})\end{array}$ & $\begin{array}{c}\text { ISM BANDI } \\
(2.4-2.48 \mathrm{GHz})\end{array}$ \\
\hline DEIYYONİZE SU & $\% 41,49$ & $\% 47$ \\
\hline ŞEKER (SÜKROZ) & $\% 56,18$ & $\% 53$ \\
\hline TUZ (NaCl) & $\% 2,33$ & - \\
\hline AGAROZ & \multicolumn{2}{|c|}{100 ml'lik karışıma 1 g eklenir } \\
\hline
\end{tabular}

ISM bandında yapılan çalışmalar için literatürde farklı içeriklerde bulunmaktadır. Bunun nedeni ISM bandı için kullanılan malzemelerin oldukça zor bulunması ve pahalı olmasıdır. Örneğin; \%58,2 deiyonize su, \%5,1 DGBE ve \%36,7 Triton ile yapılan bir çözelti yine 100 ml'lik karışıma $1 \mathrm{~g}$ agoroz ekleyerek kullanılarak fantom sıvı içeriği bazı çalışmalarda verilmiştir (Fukunaga vd., 2004; Yamaç, 2015).

Doku içinde antenin ölçümleri simülasyonda üç katmalı yapılırken, fantom sıvıda sadece deri doku oluşturularak ölçüm yapılmıştır. Çünkü literatürdeki bazı çalışmalarda ölçümler için sadece bir dokunun olmasının yeterli olduğunu kanıtlamıştır (Duan vd., 2012; Yamaç, 2015). Fantom sıvıda üç katman modelinin kullanılması zor ve pahalı olduğu için bu çalıșmada tek katman modeli uygulanmıștır.

\subsection{Antenin Yerleştirildiği Ortam (Antenna Placed in Medium)}

Yapılan çalışmada üç boyutlu doku modelinin kullanılmasının nedenlerinden bir tanesi kas, yağ ve deri dokunun vücudun hemen hemen her yerinde bulunmasıdır.

Antenin deri dokuya yerleştirilmesi anten veriminin iyi olması ve kolay cerrahi operasyon açısından düșünülmüștür. Anten, dokuda ne kadar derine koyulursa o kadar verim azalacaktır. Çünkü doku ortamı çok kayıplı bir ortamdır. Ayrıca dokular tarafından soğurma oranı daha da artacaktır. Şekil 5'de implant antenin simülasyonda doku içerisindeki konumu gösterilmiştir.

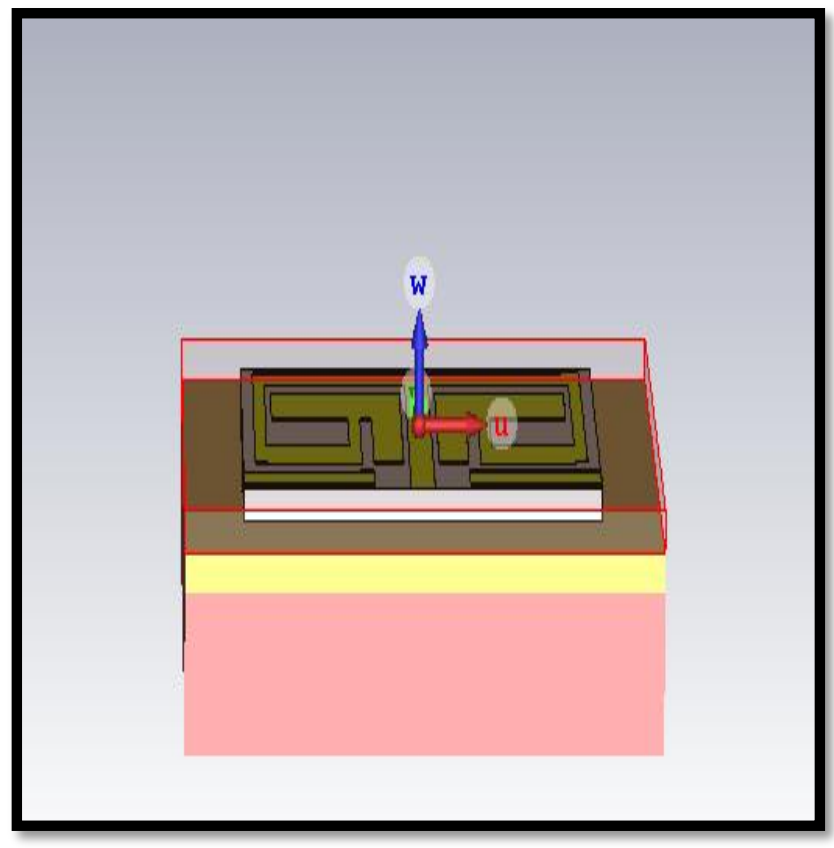

Şekil 5. Deri dokusuna yerleștirilen implant antenin konumu (Position of the implant antenna placed in the skin tissue) 
Simülasyonu yapılan ölçümlerin gerçeklenmesi için Tablo 2'de gösterildiği üzere fantom sıvı hazırlanmıştır. Hazırlanan bu sıvı Şekil 6’da gösterildiği gibi bir kap içerisine koyularak anten içine konumlandırılmıştır. Ölçümler Rohde \& Schwarz (FSH6) marka spektrum analizör kullanılarak yapılmıștır.

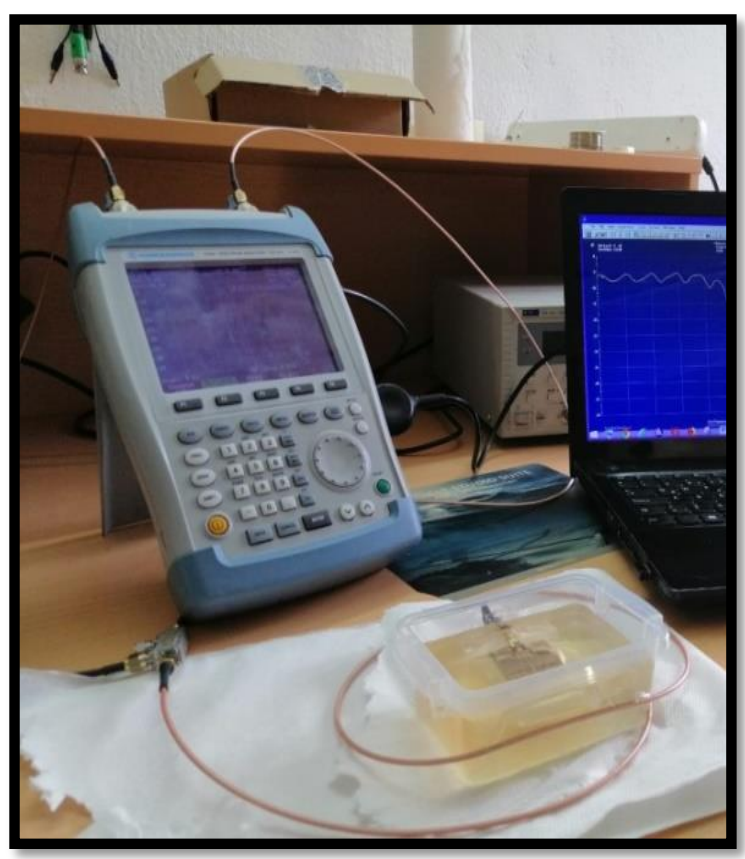

Şekil 6. Fantom sıvı ve ölçüm düzeneği (Phantom liquid and measuring device)

\section{Deneysel Sonuçlar (Experimental Results)}

Yapılan çalışmada simülasyonda implant mikroşerit antenin $\mathrm{S}_{11}$ ve SAR (özgül Soğurma Oranı) değerleri incelenmiştir. Ölçümlerin gerçeklenmesinde ise sadece implant antenin $\mathrm{S}_{11}$ sonuçları değerlendirilmiştir.

SAR için sınır değer olarak IEEE C95.1standartı $1 \mathrm{~g}$ doku için $1.6 \mathrm{~W} /$ Kg olarak belirlemiştir (Gözel, 2019). Mevcut çalışmadaki SAR değeri CST simülasyon programı ile $1 \mathrm{~W}$ giriş için ölçüm yapılmış dokunun görüntüsü ve SAR değeri Şekil 6'da sunulmuştur.

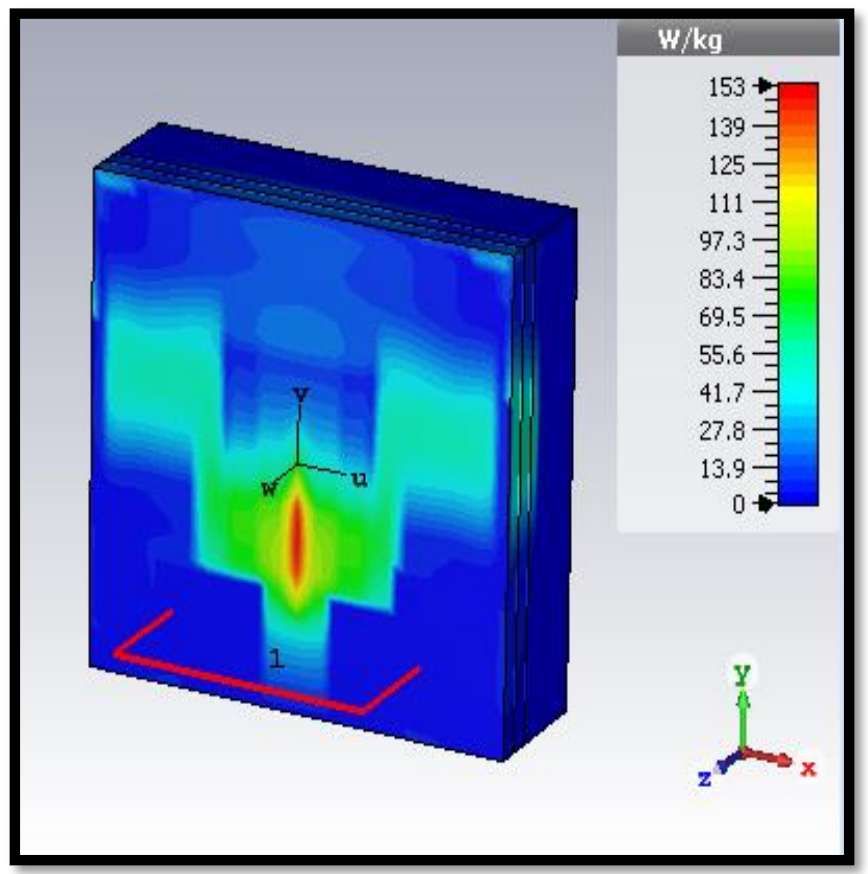

Şekil 6. Dokudaki SAR dağılımı ve sonuç skalası (SAR distribution in the tissue and result scale) 
Şekil 6'da da göründüğü gibi tasarlanan antenin maksimum SAR değeri 153 W/kg olarak belirlenmiștir. Tablo 3'de yapılan karşılaştırmaya göre gayet iyi bir değer olduğu görülmektedir. Tasarlanan mikroşeritimplant antenin $\mathrm{S}_{11}$ sonuçları ise antenin doku içinde ve dışında olmak üzere iki ayrı şekilde ölçülmüştür.

Doku dışındaki antenin Şekil 7'de S 11 grafiği verilmiștir. Şekilde de görüldüğü gibi simülasyon sonucu merkez frekansı $2.45 \mathrm{GHz}$, geri dönüş kaybı -33 dB olarak gözlemlenmiştir. Antenin gerçek ölçüm sonucu ise $2.49 \mathrm{GHz}$ de -23 dB olarak ölçülmüştür.

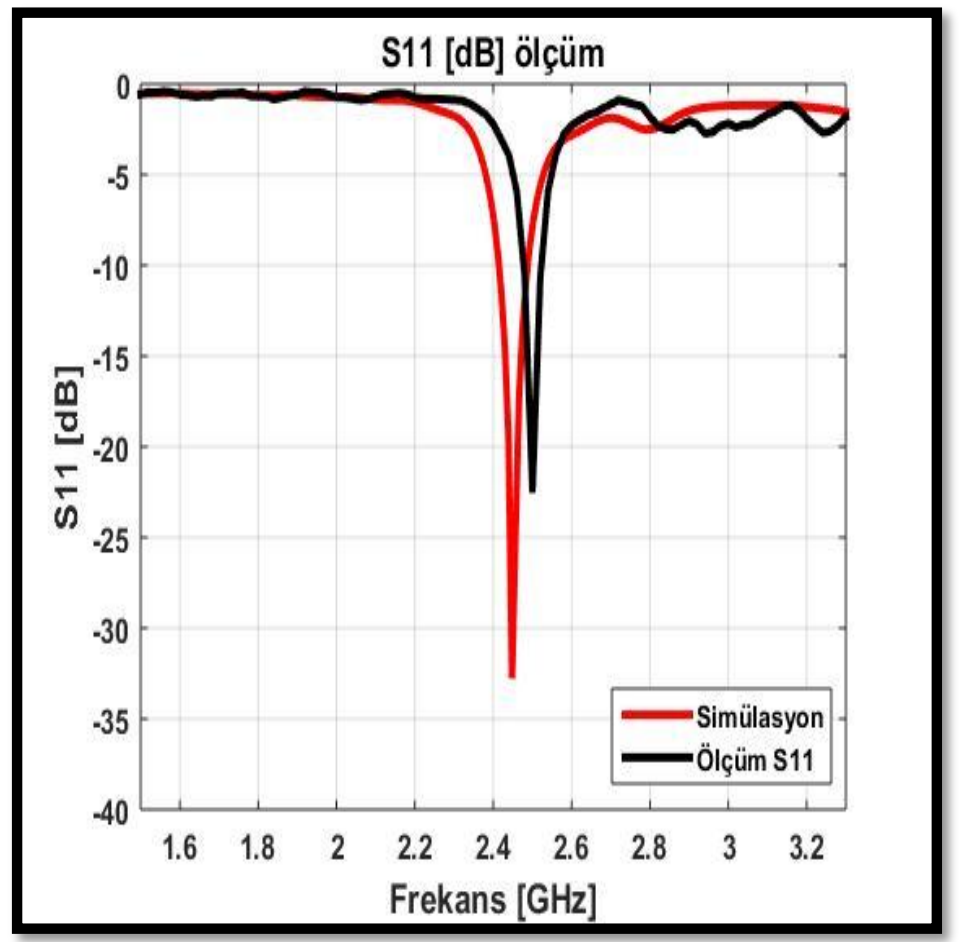

Şekil 7. Doku dışı $\mathrm{S}_{11}$ ölçüm sonuçları (Non-tissue $\mathrm{S}_{11}$ measurement results)

Şekil 8'de doku içi ölçümler için $\mathrm{S}_{11}$ grafiği verilmiştir. Grafikte de görüldüğü gibi simülasyon sonucu merkez frekansı $1.56 \mathrm{GHz}$, geri dönüş kaybı -18 dB olarak gözlemlenmiştir. Antenin fantom sıvıya konulduktan sonraki ölçüm sonucu ise $2.16 \mathrm{GHz}$ de $-41 \mathrm{~dB}$ olarak ölçülmüştür. 


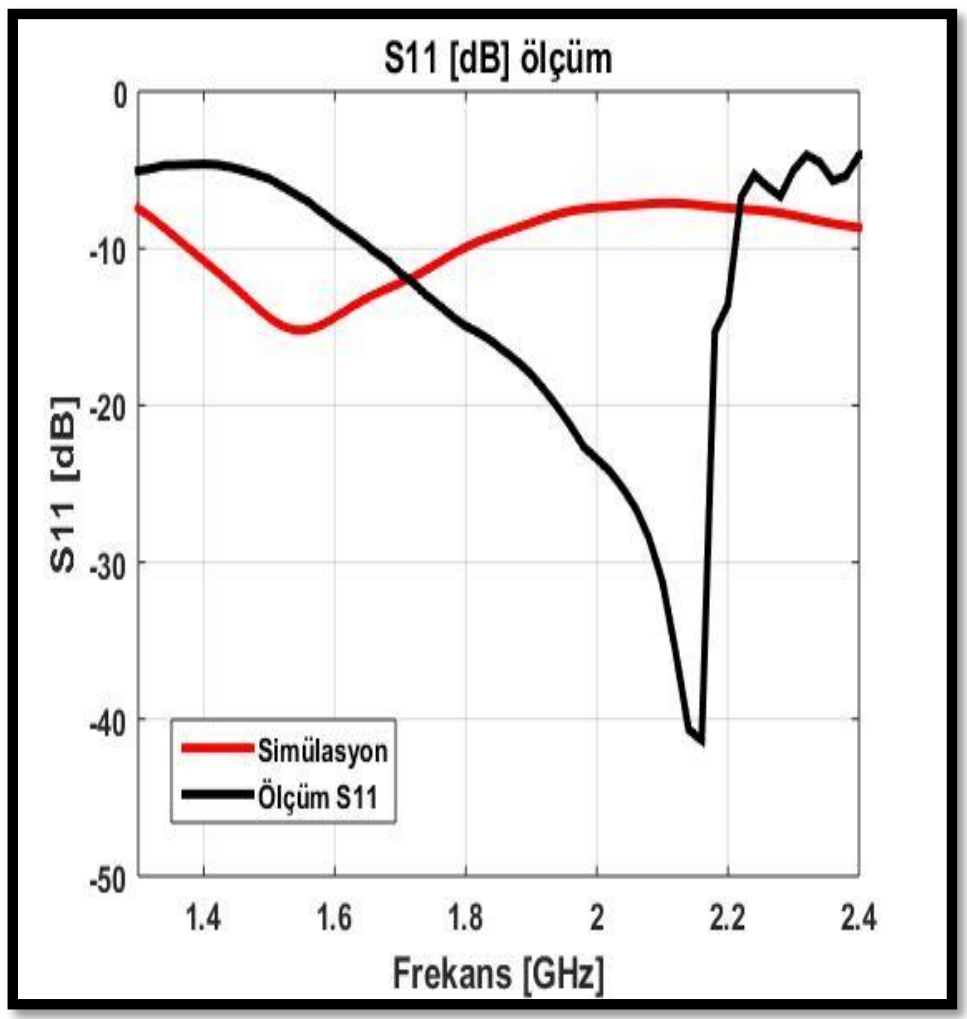

Şekil 8. Doku içi $S_{11}$ ölçüm sonuçları (In-tissue $S_{11}$ measurement results)

Yukarıdaki Şekil 7 ve Şekil 8'deki grafikler CST Microwave Studio ve spektrum analizörden alınan verilerin MATLAB programına girilerek grafikler oluşturulmuştur.

\section{Sonuç ve Tartışma (Result and Discussion)}

Bu çalışmada, doku içi uygulamalarda kullanılabilecek ISM bandında $2.45 \mathrm{GHz}$ merkez frekansında çalışan bir mikroșerit implant anten tasarımı yapılmıștır. Tasarımlar 3D elektromanyetik simülasyon yazılımı olan uzayında sonlu integral tekniğini temel alan CST Microwave Studio programı içerisinde modellenmiş ve tasarımların analizleri yapılmıștır.

Antende dielektrik malzeme olarak FR4 kullanılmıştır. Tasarlanan antenin boyutu $30 \mathrm{~mm} * 28 \mathrm{~mm} * 1.59 \mathrm{~mm}$ 'dir. Simülasyon sonucunda antenin merkez frekansı $2.45 \mathrm{GHz}$ ve geri dönüş kaybı $-33 \mathrm{~dB}$ olarak görülmüștür. Gerçek ölçüm sonucunda ise merkez frekansının $2.49 \mathrm{GHz}$ ve geri dönüș kaybı -27 dB olarak ölçülmüștür. Doku içi ölçümlerde ise simülasyon sonucu geri dönüş kaybı -18 dB, fantom sıvıya konulan antenin ise geri dönüş kaybı $41 \mathrm{~dB}$ olarak ölçülmüștür. Yapılan ölçümlerde doku dışı ölçümlerde fark yok denilecek kadar az iken doku içi ölçümlerde biraz fark oluşmuştur. Oluşan bu fark oluşturulan fantom sıvı hazırlanırken sıcaklık değerinin ve dielektrik sabitinin tam ayarlanamamasından kaynaklanması muhtemeldir. Ayrıca ölçüm simülasyon sonucu dokudaki SAR değeri $153 \mathrm{~W} / \mathrm{kg}$ olarak hesaplanmıștır. Deri dokusu içerisindeki ölçüm sonuçlarının benzetim sonuçlarıyla, oldukça uyumlu olduğu gözlemlenmiştir.

Tablo 3'de görüldüğü üzere anten parametrelerinin diğer literatürdeki bazı çalışmalarla karşılaştırılmıştır. Karşılaştırma yapılan parametreler antenin boyutu, malzemesi, bant genişliği, kazancı ve SAR değeridir.

Tablo 3'de yapılan değerlendirmeler sonucu; SAR değerinin oldukça iyi bir değerde olduğu, diğer parametrelerin ise ortalama değerlere sahip olduğu görülmüştür. Bu doğrultuda tasarımı yapılan antenin, bu alanda tercih edilebilir bir tasarım olduğu sonucuna varılmıștır.

Doku hacminin büyümesi simülasyon sürecini ciddi manada arttırmaktadır. Ayrıca ölçümlerin gerçeklenmesi için oluşturulan fantom sıvının bileşenleri olan kimyasallar oldukça pahalıdır. 0 yüzden daha az fantom sıvı oluşturmak zorunda kalınmıștır. Antenin doku içindeki konumu yapılan çalışmanın amacına göre değişiklik göstermektedir. Üç katmanlı dokuda deri ve kas doku hemen hemen aynı özellikleri gösterirken, yağ dokunun iletkenlik ve geçirgenlikte yüksek dielektriğinin ise düşük olduğu literatürdeki çalışmalardan yola çıkarak söylenebilmektedir. Geleceğin önemli araştırma konuları bunlar olacaktır. İleriki çalışmalarda; antenin 
fabrikasyonu yapılarak fantom ve canlı doku ölçümleri tekrarlanabilir ve bu ölçümler için medikal implant cihaz üretimi gerçekleștirilebilir.

Tablo 3. Mevcut çalışmanın literatürdeki diğer çalışmalarla karşılaştırılması (Comparison of the current study with other studies in the literature)

\begin{tabular}{|c|c|c|c|c|c|}
\hline Kaynak & $\begin{array}{l}\text { Boyutlar ve yapı } \\
\text { (mm* mm*mm) }\end{array}$ & $\begin{array}{c}\text { Katman } \\
\text { Malzemeleri }\end{array}$ & $\begin{array}{c}\text { Bant } \\
\text { Genişliği }\end{array}$ & $\begin{array}{c}\text { Maksimum } \\
\text { Kazanç } \\
\text { (dBi) }\end{array}$ & $\begin{array}{c}\text { SAR } \\
(\mathrm{W} / \mathrm{Kg})\end{array}$ \\
\hline \multirow{2}{*}{$\begin{array}{l}\text { Karaçolak } \\
\text { Vd. } 2008\end{array}$} & \multirow{2}{*}{$\begin{array}{l}22.5^{*} 22.5^{*} 2.54 \\
\left(1265.6 \mathrm{~mm}^{3}\right) \\
\text { PIFA }\end{array}$} & $\begin{array}{c}\text { Üst katman } \\
\text { Rogers } 3210\end{array}$ & MICS \%20.4 & 24 & - \\
\hline & & $\begin{array}{c}\text { Alt katman } \\
\text { Rogers } 3210\end{array}$ & ISM \%4.2 & 7.5 & - \\
\hline $\begin{array}{c}\text { Chein Vd. } \\
2010\end{array}$ & $\begin{array}{l}18^{*} 16^{*} 1 \\
\left(288 \mathrm{~mm}^{3}\right) \\
\text { Monopol }\end{array}$ & - & MICS \%33.5 & 24 & 797 \\
\hline \multirow{2}{*}{$\begin{array}{c}\text { Huang Vd. } \\
2011\end{array}$} & \multirow{2}{*}{$\begin{array}{c}10 * 10 * 2.54 \\
\left(254 \mathrm{~mm}^{3}\right) \\
\text { PIFA }\end{array}$} & \multirow{2}{*}{$\begin{array}{c}4 \text { katmanlı } \\
\text { Rogers } 3210\end{array}$} & MICS \%21.3 & 7 & 341 \\
\hline & & & ISM \%2.5 & 15 & 381 \\
\hline $\begin{array}{c}\text { Ha Vd. } \\
2011\end{array}$ & $\begin{array}{c}15.9 * 12.9 * 1.6 \\
\left(328.2 \mathrm{~mm}^{3}\right) \\
\text { Patch }\end{array}$ & Alt katman FR4 & MICS \%2.5 & 38 & 130.5 \\
\hline $\begin{array}{c}\text { Kiourti } \\
\text { Vd. } 2012\end{array}$ & $\begin{array}{c}12 \mathrm{~mm} \text { çapl, } 3^{*} 0.635 \\
\left(274.3 \pi \mathrm{mm}^{3}\right) \\
\text { PIFA }\end{array}$ & $\begin{array}{l}\text { Üç katmanlı } \\
\text { Rogers } 3210\end{array}$ & MICS \%10.9 & 39.1 & 324.7 \\
\hline \multirow{2}{*}{$\begin{array}{c}\text { Lie-Jie Vd. } \\
2012\end{array}$} & \multirow{2}{*}{$\begin{array}{c}19 * 19.4 * 1.27 \\
\left(487.8 \mathrm{~mm}^{3}\right) \\
\text { PIFA }\end{array}$} & $\begin{array}{l}\text { Üst katman } \\
\text { Rogers } 3210\end{array}$ & MICS \%52.6 & 28 & 324 \\
\hline & & $\begin{array}{l}\text { Alt katman } \\
\text { Rogers } 3210\end{array}$ & ISM \%5.4 & 27.6 & 314 \\
\hline \multirow{2}{*}{$\begin{array}{c}\text { Lİe-Jie Vd. } \\
2014\end{array}$} & \multirow{2}{*}{$\begin{array}{c}10.02 * 10.02 * 0.675 \\
\left(67.77 \mathrm{~mm}^{3}\right) \\
\text { PIFA }\end{array}$} & $\begin{array}{l}\text { Üst katman } \\
\text { Rogers } 3010\end{array}$ & MICS \%47.5 & 30.5 & 302.4 \\
\hline & & $\begin{array}{l}\text { Alt katman } \\
\text { Rogers } 3010\end{array}$ & ISM \%31.6 & 19.2 & 238.9 \\
\hline \multirow[b]{2}{*}{$\begin{array}{l}\text { Yamaç. } \\
2015\end{array}$} & \multirow[b]{2}{*}{$\begin{array}{c}10.5^{*} 11.5^{*} 1.27 \\
\left(153.35 \mathrm{~mm}^{3}\right) \\
\text { PIFA }\end{array}$} & $\begin{array}{l}\text { Üst katman } \\
\text { Rogers } 3010\end{array}$ & MICS \%42.1 & 39 & 369 \\
\hline & & $\begin{array}{l}\text { Alt katman } \\
\text { Rogers } 3010\end{array}$ & ISM \%5.8 & 22.9 & 396.4 \\
\hline \multirow{2}{*}{$\begin{array}{c}\text { Usluer. } \\
2017\end{array}$} & \multirow{2}{*}{$\begin{array}{c}14 * 14 * 1.27 \\
\left(248.92 \mathrm{~mm}^{3}\right) \\
\text { Patch }\end{array}$} & \multirow{2}{*}{$\begin{array}{c}\text { Katman Rogers } \\
3010\end{array}$} & MICS $\% 20$ & 39.6 & 354.1 \\
\hline & & & ISM \%6 & 26 & 368 \\
\hline $\begin{array}{l}\text { Gözel Vd. } \\
2019\end{array}$ & $\begin{array}{l}16^{*} 15^{*} 1.5 \\
\left(240 \mathrm{~mm}^{3}\right) \\
\text { Dipol }\end{array}$ & Katman FR4 & UHF \%28.8 & 25 & 396.8 \\
\hline $\begin{array}{l}\text { Mevcut } \\
\text { Çalışma }\end{array}$ & $\begin{array}{c}30 * 28 * 1.59 \\
\left(1335.6 \mathrm{~mm}^{3}\right) \\
\text { Patch }\end{array}$ & Katman FR4 & ISM \%18.7 & 14.8 & 153 \\
\hline
\end{tabular}




\section{Çıkar Çatışması (Conflict of Interest)}

Yazarlar tarafından herhangi bir çıkar çatışması beyan edilmemiştir. No conflict of interest was declared by the authors.

\section{Kaynaklar (References)}

Almari, S., Langley, R., J., Alamoudi, A., O., 2013. Improved Performance of $2.45 \mathrm{GHz}$ Implanted Patch Antenna for Wireless Communication. Antennas \& Propagation Conference, 11-12 November 2013, Loughborough, UK.

Armağan, O., Kahriman, M., 2016. 2.45 GHz, 3.7 GHz Ve 5.8 GHz Frekanslarda Çalışan Üç-Bant Yama Anten Tasarımı, Mühendislik Bilimleri Ve Tasarım Dergisi, vol. 4, pp. 189-193.

Chien, T., Cheng, C., Yang, C., Jiang, C., Luo, C., 2010. Development of Nonsuperstrate Implantable Low-Profile CPW-Fed Ceramic Antennas. IEEE Antennas and Wireless Propagation Letters, 9, 599-602.

Doddipalli, S., Kothari, A., Peshwe, P., 2017. A Low Profile Ultrawide Band Monopole Antenna for Wearable Applications. International Journal of Antennas and Propagation, 2017, India, 9 pages.

Duan, Z., Guo, Y., X., Xue, R., F., Je, M., Kwong, D., L., 2012. Differentially Fed Dual-Band Implantable Antenna for Biomedical Applications. IEEE Transactions on Antennas and Propagation, 60(12), 5587-5595.

Fukunaga, K., Watanabe, S., Yamanaka, Y., 2004. Dielectric Properties of Tissue-Equivalent Liquids and Their Effects on Specific Absorption Rate. IEEE Transactions on Electromagnetic Compatibility, 46(1), 126-129.

Gözel, M., A., Kasar, Ö., Kahriman, M., 2019. 868 MHz UHF Bandında H-Şeklinde Katlanmış İmplant Mikroşerit Dipol Anten Tasarımı. DÜMF Mühendislik Dergisi, 10(3), 797-806.

Ha, J., Kwon, K., Choi, J., 2011. Compact Zeroth-Order Resonance Antenna for Implantable Biomedical Service Applications. Electronics Letters, 47(23), 1267-1269.

Hall P. S., Hao Y., 2012. Antennas and Propagation for Body-Centric Wireless Communications, 2 nd ed., Artech House, Boston, 2012.

Huang, W., Kishk, A., A., 2011. Embedded Spiral Microstrip Implantable Antenna. International Journal of Antennas and Propagation, June 2011, 6 pages.

Karaçolak, T., Hood, A., Z., Topsakal, E., 2008. Design of a Dual-Band Implantable Antenna and Development of Skin Mimicking Gels for Continuous Glucose Monitoring. IEEE Transactions on Microwave Theory and Techniques, 56(4), 1001-1008.

Kim, J., \& Rahmat-Samii, Y., 2004. Implanted Antennas İnside a Human Body: Simulations, Designs, and Characterizations. IEEE Transactions on Microwave Theory and Techniques, 52(8), 1934-1943.

Kiourti, A., Nikita, K., S., 2012. Miniature Scalp-Implantable Antennas for Telemetry in The MICS and ISM Bands: Design, Safety Considerations and Link Budget Analysis. IEEE Transactions on Antennas and Propagation, 60(8), 3568-3575.

Kumar, S., A., Raj, M., A., Shanmuganantham, T., 2017. Analysis and Desing of CPW Fed Antenna at ISM Band for Biomedical Application. Alexandria Engineering Journal, 57, 723-727.

Lee J. H., 2015. Human Implantable Arrhythmia Monitoring Sensor with Wireless Power and Data Transmission Technique, Austin J Biosens \& Bioelectron, 1(2), 1008-1014.

Li-Jie, X., Yong-Xin, G., Wen, W., 2012. Dual-Band Implantable Antenna with Open-End Slots on Ground. IEEE Antennas and Wireless Propagation Letters, 11, 1564-1567.

Li-Jie, X., Yong-Xin, G, Wen, W., 2014. Miniaturized Dual Band Antenna for Implantable Wireless Communications. IEEE Antennas and Wireless Propagation Letters, 13, 1060-1063.

Merli, F., Bolomey, L., Zürcher, J.-F., Corradini, G., Meurville, E., \& Skrivervik, A. K. 2011. Design, Realization and Measurements of a Miniature Antenna for Implantable Wireless Communication Systems. IEEE Transactions on Antennas and Propagation, 59(10), 3544- 3555.

Polat, L., N., Ö., 2011. Elektromanyetik Alan Yayıcı Cihazların Kas Dokusunda oluşturduğu Etkinin Modellenmesi ve Analizi. Süleyman Demirel Üniversitesi, Fen Bilimleri Enstitüsü, YL Tezi, 65s, Isparta

See, T., S., P., Qing, X., Chen, Z., N., 2015. Desing and Characterization of on-Head Antenna Systems for Neural Motor Prosthesis. 9 th European Conference on Antennas and Propagation (EuCAP), 13-17 August April 2015, Lisbon Portugal.

Singh K., 2005. Biotelemetry: Could Technological Developments Assist Healthcare in Rural India, Rural and Remote Health Journal, 234(5), 1-6.

Sondas A., Ucar M. H. B., Uras E., 2014. A Dual-Band Implantable Antenna Desing, 22nd Signal Processing and Communications Applications Conference (SIU), Trabzon, Turkey, 23-25 April.

Topsakal E., 2009. Antennas for Medikal Applications: Ongoing Research and Future Challenges, International Conference on Electromagnetics in Advanced Application (ICEAA), Torino, Italy.

Usluer, M., 2017. Tümleyen Yarık Halka Elemanlarını Temel Alan İmplant Anten Tasarımı ve Üretimi. Akdeniz Üniversitesi, Fen Bilimleri Enstitüsü, YL Tezi, 51s, Antalya.

Yamaç, Y., E., 2015. Biyomedikal Uygulaması İçin İmplant Edilebilen Mikroșerit Anten Tasarımı ve Üretimi. Akdeniz Üniversitesi, Fen Bilimleri Enstitüsü, YL Tezi, 46s, Antalya.

Yang L., Vyas R., Rida A., Pan J., Tentzeris M. M., 2008. Wearable RFID-Enabled Sensor Nodes for Biomedical Applications, 2008 58 th Electronic Componenets and Technology Conference, Lake Buena Vista, FL, ABD.

Yeap, K., Voon, C., Hiraguri, T., Nisar, H., 2019. A Compact Dual-Band Implantable Antenna for Medical Telemetry. International Conference on Open Source Systems and Technologies (ICOSST), 17-19 Dec. 2015, Lahore Pakistan. 